\title{
ISOTOPE-RATIO AND BACKGROUND CORRECTIONS FOR ACCELERATOR MASS SPECTROMETRY RADIOCARBON MEASUREMENTS
}

\author{
D J DONAHUE, T W LINICK ${ }^{1}$ and A J T JULL \\ NSF-Arizona Accelerator Facility for Radioisotope Analysis \\ The University of Arizona, Tucson, Arizona 85721
}

\begin{abstract}
We present here the method we use to convert to radiocarbon ages $\left({ }^{14} \mathrm{C} /{ }^{13} \mathrm{C}\right)$ ratios measured in the Arizona Accelerator Mass Spectrometer facility. We describe the procedures we use to convert sample and standard isotope ratios to values appropriate for calculation of radiocarbon ages. We also discuss, in some detail, corrections to account for sample contamination.
\end{abstract}

\section{INTRODUCTION}

At the Arizona Accelerator Mass Spectrometry (AMS) facility, radiocarbon ages are determined by measuring the ratio $\left({ }^{14} \mathrm{C} /{ }^{13} \mathrm{C}\right)$ in a sample and comparing that ratio with a similar one measured for known standards (Linick et al 1986). The measured ratios of standards and samples are corrected to values corresponding to $\delta^{13} \mathrm{C}=-25 \%$ o using $\left({ }^{13} \mathrm{C} /{ }^{12} \mathrm{C}\right)$ ratios measured in a stable isotope mass spectrometer and the "fraction of modern," $F$, of the sample, $S$, is deduced from the equation

$$
\mathrm{F}=\frac{(14 / 13)_{\mathrm{S}[-25]}}{(14 / 13)_{1950[-25]}}
$$

In this equation, isotope ratios are indicated by the ratio of isotope mass numbers, and the $\delta^{13} \mathrm{C}$ to which the ratio has been normalized is given by the number in square brackets. For example, the ${ }^{14} \mathrm{C} /{ }^{13} \mathrm{C}$ of a sample, $\mathrm{S}$, normalized to $\delta^{13} \mathrm{C}=-25 \%$, is given as $(14 / 13)_{\mathrm{S}[-25]}$. This notation is used throughout this paper.

The radiocarbon age of the sample, $\mathrm{S}$, is calculated from the equation

$$
\text { Radiocarbon Age }=-\tau \ln \mathrm{F},
$$

where $\tau$ is the Libby mean life (8033 years). In the following paragraphs we describe the conversion of measured isotope ratios to forms that can be used in equations (1) and (2). The method of measuring isotope ratios and the errors in such measurements are described by Linick et al (1986). Under Contamination Corrections, below, we present the form of background corrections applied to isotope ratios measured in our laboratory.

\section{ISOTOPE-RATIO CALCULATIONS}

According to Stuiver and Polach (1977), most radiocarbon laboratories calculate the radiocarbon age of a sample, $\mathrm{S}$, from the equation

\footnotetext{
${ }^{1}$ Deceased
} 


$$
\text { Radiocarbon Age }=-8033 \text { ln } \frac{A_{\text {SN }}(1950)}{A_{\mathrm{ON}}(1950)}
$$

where $A_{S N}$ is the specific activity of the sample, $A_{S}$, normalized to $\delta^{13} \mathrm{C}=-25 \%$ o by the equation

$$
A_{S N}=A_{S}\left\{\frac{1-\frac{25}{1000}}{1+\frac{\delta^{13} C_{s}}{1000}}\right\}^{2} .
$$

$\mathrm{A}_{\mathrm{ON}}$ is a standard specific activity obtained from the specific activity, today, of NBS "old" oxalic acid (SRM $4990 \mathrm{~B}$ ) normalized to $\delta^{13} \mathrm{C}=-19 \%$, using the equation

$$
A_{\mathrm{ON}}=0.95 \mathrm{~A}_{\mathrm{Ox}}\left\{\frac{1-\frac{19}{1000}}{1+\frac{\delta^{13} \mathrm{C}_{\mathrm{ox}}}{1000}}\right\}^{2} \text {. }
$$

The numbers (1950) in Eq (3) indicate that specific activities should be measured in AD 1950, and the resultant age will be in radiocarbon years before present (BP), where present is the year $A D$ 1950. Since both specific activities have the same decay rate, it is in fact, only necessary to measure the numerator and denominator of the logarithm at approximately the same time.

The normalized standard specific activity, $A_{O N}$, is related to the absolute international standard specific activity, $\mathrm{A}_{\mathrm{abs}}$, by the equation

$$
A_{a b s}=A_{O N} e^{+\lambda(y-1950)}
$$

where $y$ is the year of measurement and $1 / \lambda=8267$ years. Since $A_{a b s}$ is the specific activity of a hypothetical (1950) atmospheric carbon level normalized to $\delta^{13} \mathrm{C}=-25 \%$ o (Stuiver \& Polach 1977), $A_{O N}$ is the specific activity of that hypothetical 1950 atmosphere with $\delta^{13} \mathrm{C}=-25 \%$, decayed to the present. In the following discussion, we label $\mathrm{A}_{\mathrm{ON}}$ as $\mathrm{A}_{1950[-25]}$ to indicate that it is a specific activity, normalized to $\delta^{13} \mathrm{C}=-25 \%$ which, when used in Eq (3) with a coincidentally measured and appropriately normalized sample specific activity, $A_{S N}$, yields a conventional radiocarbon age in years before AD 1950.

In a later paper, Stuiver (1983) presents results of a series of experiments relating the specific activities of "old" oxalic acid and "new" oxalic acid, NOX (NBS SRM 4990 C). These results can be summarized as

$$
0.95 \mathrm{~A}_{\mathrm{OX}[-19]}=0.7459 \mathrm{~A}_{\mathrm{NOX}[-25]}
$$

where the numbers in square brackets are the $\delta^{13} \mathrm{C}$ values to which the activities are normalized. The results of Eqs (5) and (7) and the discussion in the paragraph above are combined to give

$$
\mathrm{A}_{1950[-25]}=0.95 \mathrm{~A}_{\mathrm{OX}[-19]}=0.7459 \mathrm{~A}_{\mathrm{NOX}[-25]} .
$$


In what follows, we will deduce equations equivalent to Eqs (4) and (8) for use in Eqs (1) and

(2) when isotope ratios are measured instead of specific activities.

Specific activity is proportional to the ratio of ${ }^{14} \mathrm{C}$ atoms to total carbon atoms in a sample or standard, so that Eq (8) can be written as

$$
\left(\frac{14}{12+13}\right)_{1950[-25]}=0.95\left(\frac{14}{12+13}\right)_{\mathrm{ox}[-19]}=0.7459\left(\frac{14}{12+13}\right)_{\mathrm{NoX}[-25]} .
$$

To better than one part in $10^{4}$, the ratios in Eq (9) can be approximated as $(14 / 12+13)=(14 / 12)$, and

$$
(14 / 12)_{1950[-25]}=0.95(14 / 12)_{\mathrm{Ox}_{[-19]}}=0.7459(14 / 12)_{\mathrm{NOX}[-25]} \text {. }
$$

If one measures (14/12) ratios, $\mathrm{Eq}(10)$ is the equation to be used to obtain the denominator of Eqs (1) and (2) from measurements on NBS oxalic acid standards. However, at Arizona, we measure (14/13) ratios, so that Eq (10) must be further modified. This modification is made by noting that for a sample, $S$,

$$
(14 / 12)_{\mathrm{S}}=(14 / 13)_{\mathrm{s}}(13 / 12)_{\mathrm{S}}=(14 / 13)_{\mathrm{S}}\left(1+\frac{\delta^{13} C_{\mathrm{s}}}{1000}\right)(13 / 12)_{\mathrm{PDB}},
$$

where PDB is a reference standard, so that Eq (10) becomes

$(0.975)(14 / 13)_{1950[-25]}=(0.95)(0.981)(14 / 13)_{\mathrm{ox}_{[-19]}}=0.7459(0.975)(14 / 13)_{\mathrm{Nox}[-25]}$

or

$$
(14 / 13)_{1950[-25]}=0.9558(14 / 13)_{\mathrm{ox}[-19]}=0.7459(14 / 13)_{\mathrm{NOX}[-25]} .
$$

Finally, we wish to change the third term of $\mathrm{Eq}(12)$ to reflect the fact that in our laboratory we measure $(14 / 13)_{\text {Nox }}$ with $\delta^{13} \mathrm{C}=-17.8 \%$. To do this, we use Eq (1) in Stuiver (1983), namely

$$
A_{\text {Nox }[-25]}=A_{\text {Nox }[-17.8]}\left\{\frac{0.975}{0.982}\right\}^{2}
$$

which relates specific activities for new oxalic acid for $\delta^{13} \mathrm{C}=-25 \%$ and $-17.8 \%$. As pointed out above, specific activities are essentially equal to (14/12) ratios and the square of the bracketed term in Eq (13) reflects the fact that to change from a (14/12) ratio (or specific activity) normalized to a particular value of $\delta^{13} \mathrm{C}$ to the $(14 / 12)$ ratio with a different value of $\delta^{13} \mathrm{C}$, one must apply the appropriate correction twice. However, to make a similar change to (14/13) ratios, one must apply the isotope correction only once, so that 


$$
(14 / 13)_{\mathrm{NOX}[-25]}=\frac{\left(1-\frac{25}{1000}\right)}{\left(1-\frac{17.8}{1000}\right)}(14 / 13)_{\mathrm{NOX}[-17.8]}=\left(\frac{0.975}{0.9822}\right)(14 / 13)_{\mathrm{NOX}[-17.8]}
$$

giving, from Eq (12)

$$
(14 / 13)_{1950[-25]}=0.9558(14 / 13)_{\mathrm{Ox}[-19]}=0.7404(14 / 13)_{\mathrm{Nox}[-17.8]} \text {. }
$$

Thus, the denominator of Eq (1) is obtained by measuring the (14/13) ratios of "old" and/or "new" oxalic acid and multiplying them by the appropriate factors from Eq (15) to obtain $(14 / 13)_{1950[-25]}$. In practice, we measure (14/13) for both OX and NOX for every target-wheel loading, and calculate an average (14/13) ${ }_{1950[-25]}$. To verify proper operation of the instrument, we also obtain the ratio of $(14 / 13)_{\mathrm{NOX}[-17.8]}$ and $(14 / 13)_{\mathrm{Ox}[-19]}$, which, as can be seen from Eq (16), should be equal to 1.2909 .

The numerator for $\mathrm{Eq}(1)$ is obtained by correcting the measured (14/13) ratio of a sample with $\delta^{13} \mathrm{C}_{S}$, that is $(14 / 13)_{S[\delta]}$, by an equation of the form of $\mathrm{Eq}(14)$, namely:

$$
(14 / 13)_{\mathrm{S}[-25]}=(14 / 13)_{\mathrm{S}[\delta]}\left[\frac{1-\frac{25}{1000}}{1+\frac{\left(\delta^{13} \mathrm{C}\right)_{\mathrm{s}}}{1000}}\right]
$$

This is the exact form of an equation that was presented as an approximation in Linick et al (1986).

To obtain a radiocarbon age from measured (14/13) isotope ratios that is equivalent to the age one would obtain by measuring specific activities and using Eq (3): (a) measured values of $(14 / 13)_{\mathrm{OX}[-19]}$ and $(14 / 13)_{\mathrm{NOX}[-17.8]}$ are converted to $(14 / 13)_{1950[-25]}$ using Eq (15); (b) $(14 / 13)_{\mathrm{S}[\delta]}$ ratios are converted to $(14 / 13)_{S[-25]}$ using Eq (16); and (c) results from (a) and (b) are used in Eq (1) and (2). When this is done, we obtain

$$
\text { Radiocarbon Age }=-\tau \text { en }\left\{\frac{\left[\frac{0.975}{\left.1+\frac{\delta^{13} \mathrm{C}_{\mathrm{s}}}{1000}\right](14 / 13)_{\mathrm{S}[\delta]}}\right.}{(0.9558)(14 / 13)_{\mathrm{Ox}[-19]}}\right\}
$$

or

$$
\text { Radiocarbon Age }=-\tau \text { ln }\left\{\frac{\left[\frac{0.975}{\left.1+\frac{\delta{ }^{13} \mathrm{C}_{\mathrm{s}}}{1000}\right](14 / 13)_{\mathrm{S}[\delta]}}\right.}{(0.7404)(14 / 13)_{\mathrm{Nox}[-17.8]}}\right\}
$$




\section{CONTAMINATION CORRECTIONS}

A correction is necessary in AMS radiocarbon measurements because samples acquire a small amount of contamination, generally called background, in the process of converting them from their initial form to graphite. There is probably also an instrument background, but at the present time, the instrument background correction is much less than the contamination correction, and is included as part of the contamination correction. In the discussion that follows, we assume that all isotope ratios are corrected to $\delta^{13} \mathrm{C}=-25 \%$, and the square-bracketed subscripts used to indicate $\delta^{13} \mathrm{C}$ of isotope ratios are not included.

To determine the magnitude of the contamination correction, blank targets are made from material containing no ${ }^{14} \mathrm{C}$ and measurements are made of the quantity

$$
f=\frac{(14 / 13)_{B}}{(14 / 13)_{\text {std }}}=\frac{\frac{(14 / \mathrm{sec})_{\mathrm{C}}}{(13 / \mathrm{sec})_{\mathrm{C}}+(13 / \mathrm{sec})_{\mathrm{M}}}}{(14 / 13)_{\text {std }}}
$$

where the subscripts $B, C$, and std signify blank, contamination and standard quantities, and $M$ denotes the matrix material of the blank target. The matrix material usually used to produce blank targets is graphite provided by the National Institute of Standards and Technology (NIST, formerly NBS). The use of this material allows us to: (a) determine the amount of ${ }^{14} \mathrm{C}$ in the original graphite, (b) combust the graphite to $\mathrm{CO}_{2}$ and reconvert the $\mathrm{CO}_{2}$ to graphite in our sample preparation lines, and (c) measure the ${ }^{14} \mathrm{C}$ in the processed graphite. The amount of ${ }^{14} \mathrm{C}$ per gram of graphite observed in (a) is approximately one-fifth of that determined in (c).

The actual value of the quantity, $\mathrm{f}$, in Eq (18) depends on the choice of standard material. For convenience, we use as a standard the ratio $(14 / 13)_{1950[-25]}$. This is often referred to as the (14/13) ratio of modern material, and its value in terms of the (14/13) ratios of the NBS oxalic acids is given in Eq (15). Multiple measurements over many months using many different blank targets yield values for $f$ and its standard deviation for a one-milligram blank sample of

$$
f=\left\{\frac{(14 / 13)_{B}}{(14 / 13)_{1950}}\right\}_{\text {one-milligram blank }}=0.004 \pm 0.001 .
$$

The standard deviation is deduced from the scatter about their mean of many measurements on different blank samples. It is larger than the standard deviation one would obtain from pure counting statistics and includes the spread of values of $f$ resulting from small variations in contamination during target preparation. Nevertheless, this standard deviation is assumed to represent the statistical distribution of measured values of $f$ about their mean value.

Measurements of the quantity, $\mathrm{f}$, on blank samples of various masses indicate that, as a function of mass, M,

$$
f(M)=\frac{f(\text { one } \mathrm{mg})}{M}=\frac{0.004 \pm 0.001}{M}
$$


where $\mathrm{M}$ is the mass of the sample in milligrams. For example, for a 100 -microgram sample,

$$
\mathrm{f}(100 \mu \mathrm{g})=0.04 \pm 0.01
$$

This dependence is just what one would expect if the mass of contaminant introduced during target fabrication was constant, independent of the size of the sample itself.

To describe the manner in which isotope ratios are corrected for contamination, consider the measured ratio, $(14 / 13)_{m}$, for a sample $S$,

$$
(14 / 13)_{\mathrm{m}}=\frac{(14 / \mathrm{sec})_{\mathrm{s}}+(14 / \mathrm{sec})_{\mathrm{c}}}{(13 / \mathrm{sec})_{\mathrm{s}}+(13 / \mathrm{sec})_{\mathrm{c}}},
$$

where $S$ and $C$ denote isotopes from the sample and contaminative materials, respectively. This equation can be rewritten as

$$
(14 / 13)_{\mathrm{m}}=(14 / 13)_{\mathrm{s}} \frac{\left\{1+\frac{(14 / \mathrm{sec})_{\mathrm{C}}}{(14 / \mathrm{sec})_{\mathrm{s}}}\right\}}{1+\frac{(13 / \mathrm{sec})_{\mathrm{c}}}{(13 / \mathrm{sec})_{\mathrm{s}}}} .
$$

Before rewriting Eq (20), we introduce the assumption that the contaminating material is modern (1950) material. We show in the appendix that this is not a necessary assumption, but its introduction simplifies the considerations that follow. With this assumption, namely that $(14 / 13)_{C}$ $=(14 / 13)_{1950}$, the quantity, $\mathrm{f}$, defined in $\mathrm{Eq}(18)$, can also be written as

$$
\mathrm{f}=\frac{(13 / \mathrm{sec})_{\mathrm{C}}}{(13 / \mathrm{sec})_{\mathrm{C}}+(13 / \mathrm{sec})_{\mathrm{M}}},
$$

and, to first order in $\mathrm{f}$,

$$
f=\frac{(13 / \mathrm{sec})_{\mathrm{c}}}{(13 / \mathrm{sec})_{\mathrm{M}}}=\frac{(13 / \mathrm{sec})_{\mathrm{c}}}{(13 / \mathrm{sec})_{\mathrm{s}}}
$$

The second equality is true when the sample, $\mathrm{S}$, has the same graphite mass as the matrix, $M$, used to determine f. Using Eq (22), the ratio $\frac{(14 / \mathrm{sec})_{c}}{(14 / \mathrm{sec})_{S}}$ in Eq (20) can be written

$$
\frac{(14 / \mathrm{sec})_{\mathrm{c}}}{(14 / \mathrm{sec})_{\mathrm{s}}}=\frac{(14 / \mathrm{sec})_{\mathrm{C}} /(13 / \mathrm{sec})_{\mathrm{s}}}{(14 / 13)_{\mathrm{s}}}=\frac{\mathrm{f}(14 / 13)_{\mathrm{c}}}{(14 / 13)_{\mathrm{s}}}=\frac{\mathrm{f}(14 / 13)_{1950}}{(14 / 13)_{\mathrm{s}}}
$$


so that $\mathrm{Eq}(20)$ can be rewritten as

$$
(14 / 13)_{\mathrm{S}}=(14 / 13)_{\mathrm{m}}(1+\mathrm{f})-\mathrm{f}(14 / 13)_{1950} .
$$

The fraction of modern of the sample, $F$, in terms of the fraction of modern, measured, $F_{m}$, is obtained by dividing both sides of Eq (24) by $(14 / 13)_{1950}$. Since we have assumed that the contamination material is modern, no blank correction is necessary to the measured ratio, $(14 / 13)_{1950}$, and

$$
F=F_{m}(1+f)-f
$$

where

$$
F_{m}=\frac{(14 / 13)_{m}}{(14 / 13)_{1950}}
$$

In a slightly different form,

$$
F=F_{m}\left[1-f\left\{\frac{1}{F_{m}}-1\right\}\right],
$$

and the term in square brackets is the blank correction factor, $(\mathrm{BCF})$.

For a modern (1950) sample, $F_{m}=1$, and the blank correction factor is unity. For a onemilligram sample with $F_{m}=0.7$, corresponding to a radiocarbon age of ca $3000 \mathrm{BP}, \mathrm{f}=0.004 \pm$ 0.001 , and the correction factor is

$$
\mathrm{BCF}=0.9983 \pm 0.0004 \text {. }
$$

The range from $3000 \mathrm{BP}$ to modern covers those ages for which the highest precision is usually desired. As can be seen, for one-milligram samples, background corrections in this range contribute $<0.1 \%(1 \%)$ to uncertainties. However, for a 100 -microgram sample with $F_{m}=0.7$, the $\mathrm{BCF}=0.983 \pm 0.005$. written

Finally, in the limit as $1 / \mathrm{F}_{\mathrm{m}}>1\left(\mathrm{~F}_{\mathrm{m}} \leq 0.1\right.$; radiocarbon age $\left.\geq 20,000 \mathrm{BP}\right), \mathrm{Eq}(26)$ can be

$$
F=F_{m}-f \text {. }
$$

The minimum value of $\mathrm{F}$ that can be measured is defined as

$$
F=F_{m}-f \geq 2 \Delta f
$$

For a one-milligram sample, where $\Delta \mathrm{f}=0.001$, this limit corresponds to a maximum age of 49,900 years. For a sample with a mass of 100 micrograms, the maximum age that can be measured at present with our instrument is ca 30,000 years. 


\section{ACKNOWLEDGMENTS}

The section on Isotope-Ratio Calculations, above, was formulated in its entirety from notes of TW Linick, who was certainly one of the world's experts in radiocarbon measurements. His expertise and his gentle personality are sorely missed in this laboratory. This work was supported in part by NSF grant EAR 8822292.

\section{REFERENCES}

Linick, TW, Jull, AJT, Toolin, LJ and Donahue, DJ 1986 Operation of the NSF-Arizona Accelerator Facility for Radio-Isotope Analysis and results from selected collaborative research projects. In Stuiver, M and Kra, RS eds, Internatl ${ }^{14} \mathrm{C}$ conf, 12th, Proc. Radiocarbon 28(2A): 522-533.

Stuiver, M 1983 International agreements and the use of the new oxalic-acid standard. In Stuiver, M and Kra, RS, eds, Internatl ${ }^{14} \mathrm{C}$ conf, 11th, Proc. Radiocarbon 25(2): 793-795.

Stuiver, M and Polach, HA 1977 Discussion: Reporting of ${ }^{14} \mathrm{C}$ data. Radiocarbon 19(3): 355-363.

\section{APPENDIX}

If, instead of assuming that $(14 / 13)_{C}=(14 / 13)_{1950}$, we use $(14 / 13)_{C}=g(14 / 13)_{1950}$, then Eq (24) becomes

$$
(14 / 13)_{\mathrm{s}}=(14 / 13)_{\mathrm{m}}(1+\mathrm{f} / \mathrm{g})-\mathrm{f}(14 / 13)_{1950},
$$

and

$$
(14 / 13)_{1950}=\left\{(14 / 13)_{1950}\right\}_{\text {measured }}\left(\frac{1+\mathrm{f} / \mathrm{g}}{1+\mathrm{f}}\right) \text {, }
$$

so that $\mathrm{Eq}(26)$ becomes

$$
F=F_{m} \frac{\left(1+f / g-f / F_{m}\right)}{\frac{1+f / g}{1+f}}
$$

If $\mathrm{f} / \mathrm{g} \ll 1$, then, to first order in $\mathrm{f}$ and $\mathrm{f} / \mathrm{g}, \mathrm{Eq}(\mathrm{A} 3)$ can be written

$$
F=F_{m}\left(1+f-f / F_{m}\right)
$$

which is identical with Eq (25). Thus, if $f=0.004$, Eq (6) is correct for $g z$ or 0.04 , or $(14 / 13)_{\mathrm{C}} \geq 0.04(14 / 13)_{1950 \text {. }}$ 